\title{
Evolution of Very High Frequency Power Supplies
}

Knott, Arnold; Andersen, Toke Meyer; Kamby, Peter; Pedersen, Jeppe Arnsdorf; Madsen, Mickey Pierre; Kovacevic, Milovan; Andersen, Michael A. E.

Published in:

I E E E Journal of Emerging and Selected Topics in Power Electronics

Link to article, DOI:

10.1109/JESTPE.2013.2294798

Publication date:

2013

Document Version

Early version, also known as pre-print

Link back to DTU Orbit

Citation (APA):

Knott, A., Andersen, T. M., Kamby, P., Pedersen, J. A., Madsen, M. P., Kovacevic, M., \& Andersen, M. A. E. (2013). Evolution of Very High Frequency Power Supplies. I E E E Journal of Emerging and Selected Topics in Power Electronics, 2(3), 386-394. https://doi.org/10.1109/JESTPE.2013.2294798

\section{General rights}

Copyright and moral rights for the publications made accessible in the public portal are retained by the authors and/or other copyright owners and it is a condition of accessing publications that users recognise and abide by the legal requirements associated with these rights.

- Users may download and print one copy of any publication from the public portal for the purpose of private study or research.

- You may not further distribute the material or use it for any profit-making activity or commercial gain

- You may freely distribute the URL identifying the publication in the public portal 


\title{
Evolution of Very High Frequency Power Supplies
}

\author{
Arnold Knott* Member, IEEE, Toke M. Andersen* Student Member, IEEE, Peter Kamby* , Jeppe A. Pedersen*, \\ Mickey P. Madsen* Student Member, IEEE, Milovan Kovacevic* Student Member, IEEE, Michael A.E. Andersen* \\ Member, IEEE * Technical University of Denmark \\ Ørsteds Plads, bygning 349, 2800 Kongens Lyngby, Denmark \\ Telefon: +45 452534 90, Email: akn@elektro.dtu.dk
}

(Submission to "Special Issue on Miniaturized Power Electronics Systems, 2013")

\begin{abstract}
The ongoing demand for smaller and lighter power supplies is driving the motivation to increase the switching frequencies of power converters. Drastic increases however come along with new challenges, namely the increase of switching losses in all components. The application of power circuits used in radio frequency transmission equipment helps to overcome those. However those circuits were not designed to meet the same requirements as power converters. This paper summarizes the contributions in recent years in application of very high frequency (VHF) technologies in power electronics, shows results of the recent advances and describes the remaining challenges. The presented results include a self-oscillating gate-drive, air core inductor optimizations, an offline LED driver with a power density of $8.9 \mathrm{~W} / \mathrm{cm}^{3}$ and a $120 \mathrm{MHz}, 9 \mathrm{~W}$ DC powered LED driver with $89 \%$ efficiency as well as a bidirectional VHF converter. The challenges to be solved before VHF converters can be used effectively in industrial products are within those three categories: components, circuit architectures and reliability testing.
\end{abstract}

Index Terms-VHF circuits, power conversion, DC-DC power converters, resonant inverters, zero voltage switching

\section{INTRODUCTION}

The continuing trend of miniaturization in industrial and consumer electronics is continuously driving a demand for smaller power supplies. Weight and cost reduction demands accompany this trend. Within power supplies the major size, weight and cost drivers are typically the passive components. Increasing the switching frequency of power converters can reduce the size, weight and therefore the cost of those. For substantial size and weight reduction, the switching frequencies are increased up to the very high frequency (VHF) band (30 $\mathrm{MHz}$ to $300 \mathrm{MHz}$ ), which leads to a merge in circuit technologies used in radio frequency transmitters [1]-[6] and the classical power electronics circuits.

The VHF amplifiers are designed for DC-AC conversion, where the AC simultaneously is the switching frequency. Generally those circuits [1], [2] drive a known load impedance, typically a $50 \Omega$ antenna. Traditionally the topologies used for those circuits have been characterized as classes with running labels following the alphabet. Class-A, class-B and class-C are described in [2], [7]. These classes are characterized through the relative amount of time, the power transistor is conducting the load current with respect to the period of the VHF signal. For class-A the transistor conducts the load current $50 \%$ of the time. Class-B operates between $25 \%$ and $50 \%$ and class-C between $0 \%$ and $25 \%$. This leads to theoretical maximum achievable efficiencies of $50 \%$, up to $78.5 \%$ and up to $100 \%$ for class-A, B and C respectively. Their power electronics counter parts are linear regulators. Class-D is described in [8] and the first power circuit topology, that allows for theoretical $100 \%$ efficiency under all operating conditions. The equivalent are strictly all hard-switched power converters. Class-E as described in [3], [4] and class-F as demonstrated in [5], [6] correspond to all power converters, that apply zero voltage switching (ZVS) and zero-current switching (ZCS) techniques respectively.

Similarly to switch-mode power supplies, those VHF amplifiers convert the constant supply voltages into a high-frequent voltage by operating power semiconductors in the triode region only. The major difference is that VHF amplifiers do not convert the energy back into a constant voltage or current level. Numerous research works have been published [9]-[20], filling this gap and making VHF technologies available for power electronics. This paper describes the individual contributions of those in greater detail. However there are still some challenges left, before VHF switch-mode power supplies can relieve their advantages for products in industrial and consumer electronics.

This paper elaborates on the most recent advances, showing prototypes and measurement results in section II. Section III describes the remaining challenges based on previous work and characterizes them. Section IV concludes the paper.

\section{RECENT AdVANCES}

Recent research results enhanced the state-of-the art in VHF converters. Most of the work in recent years has focused on class-E derived topologies.

\section{A. Optimal operation}

The class-E based power circuits allow for a second degree of soft switching. Despite turning the power switches on, when the voltage across them is zero (ZVS), also the derivatives of these signals are taken into account. This is called ZdVS and ZdCS respectively. The technique has been applied to power converters in [19]. The schematic in Fig. 1 shows the adoption of the principles of a class-E oscillator, e.g. shown in [21][23], to a class-E based power self-oscillating VHF converter (DC-DC) [19], [24]. A converter achieving both ZVS and ZdVS at all times operates in optimal mode.

Other implementation replaced either the resonant tank [25], 


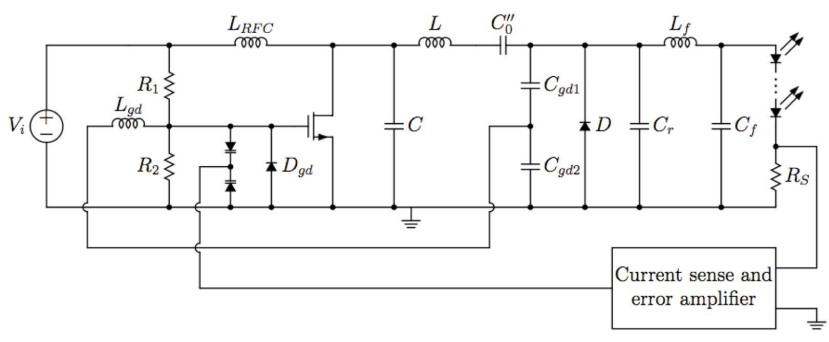

Fig. 1: Schematic of a self-oscillating VHF converter [24] with LED load.

[26] or the input inductor [11], [27] with a transmission line. The resulting waveforms of this circuit have been reported in e.g. [28]-[33] and Fig. from 2 repeats the simulated waveforms of this converter, where $v_{s}$ and $i_{s}$ are the voltage and the current across and through the switch and $v_{D}$ and $i_{D}$ are voltage and current across and through the rectifier diode. $v_{G}$ is the control signal of the power switch and $V_{o}$ and $V_{i}$ are input and output voltages of the converter. The top graph $v_{s}$ visualizes the optimization of the converter for both ZVS and ZdVS.

Fig. 3 is a photograph of the implementation of this converter. The overall efficiency of the $97 \mathrm{MHz}$ converter is $55 \%$.

The advantage of this converter is, that it is based on a widely documented circuit topology from the communication electronics applications. As implemented here, it also provides means of output regulation. The downside is the voltage stress across the power switch, 3.6 times higher as in hard-switched converters.

\section{B. Suboptimal operation}

Due to the tight adjustment of the turn on instance of the power switch for achieving ZVS and ZdVS the degrees of freedom in this converter are low. That limits the input and output voltage ranges. Furthermore the efficiency is not acceptable. In this case, the majority of the losses are due to conduction losses in the power semiconductors, which are due to the on-resistance of the power switch. As the gate voltage is not significantly higher than the threshold voltage, the devices minimum on-resistance could not be achieved.

Suboptimal operation of class-E converters as described in [4] opened for higher degrees of freedom in the design of class-E based DC-DC converters. This means that the ZdVS condition is only fulfilled under nominal load conditions and only ZVS is fulfilled otherwise. The resulting converter waveform in the optimal and suboptimal operating regions are shown in Fig. 4. The effects of these operation mode as described in [34] have been extended in [20] to LED lighting applications.

Note that the body diode of the MOSFET is conducting in the beginning of the MOSFETs conduction period. This is due to wrong timing in the turn-on of the power device. The energy lost in the body diode ruins the efficiency of this particular converter.

Furthermore [20] provides a detailed analysis of the power components parasitics and the effect of their nonlinearities. The basis for this analysis has been, among others, laid in

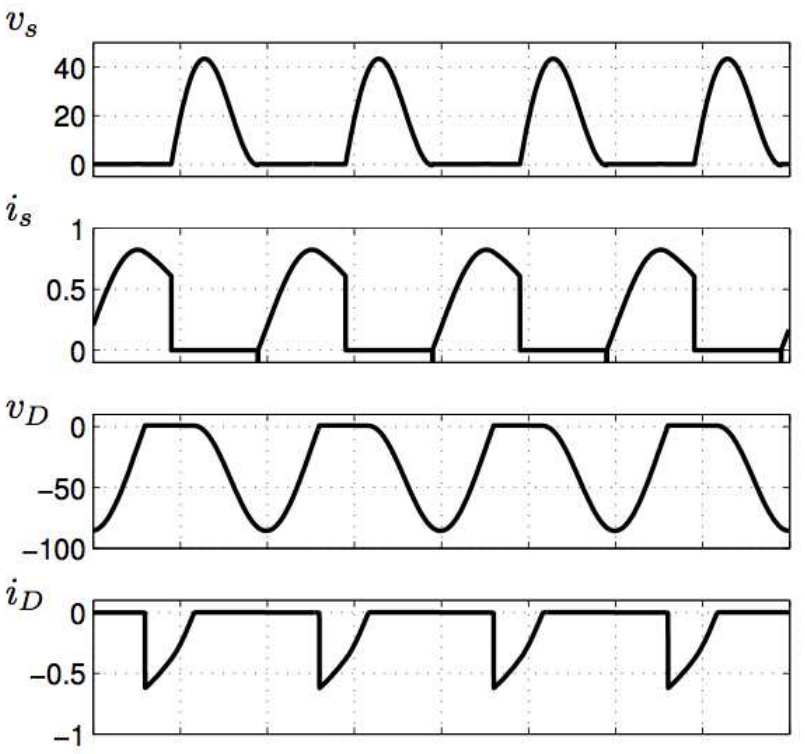

$v_{G}$
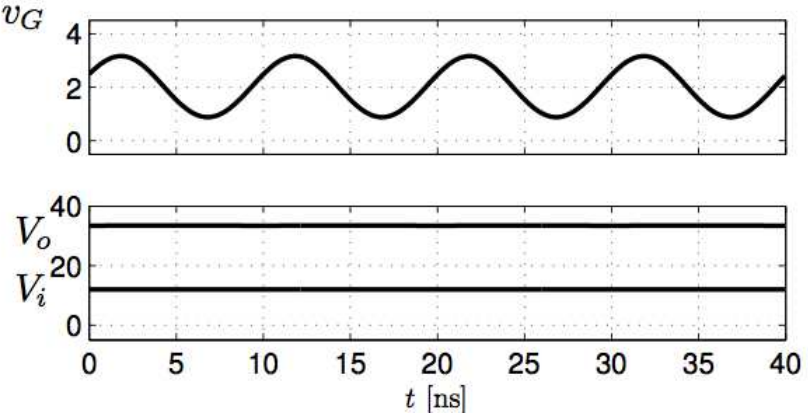

Fig. 2: Simulated waveforms for a ZVS and ZdVS class-E based converter from [19].

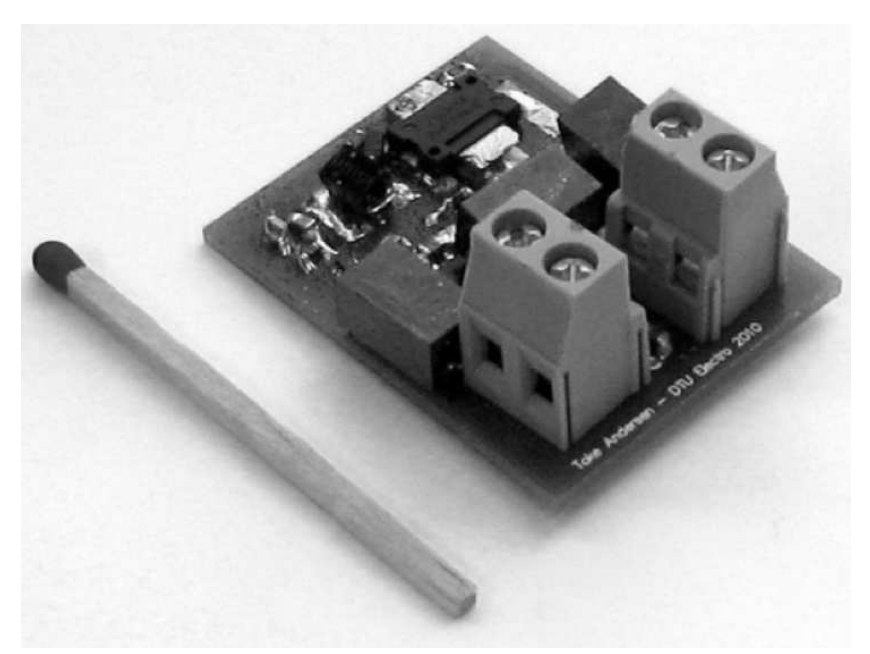

Fig. 3: Photograph of the self-oscillating VHF converter from [24].

[35], [36] for the analysis of class-E amplifiers, which is fully applicable to class-E based power converters when tuning the rectifier to act as a an ohmic load. The most relevant parasitics of the power switch are the input and output capacitances. The later is the most critical for the design of the converter. 


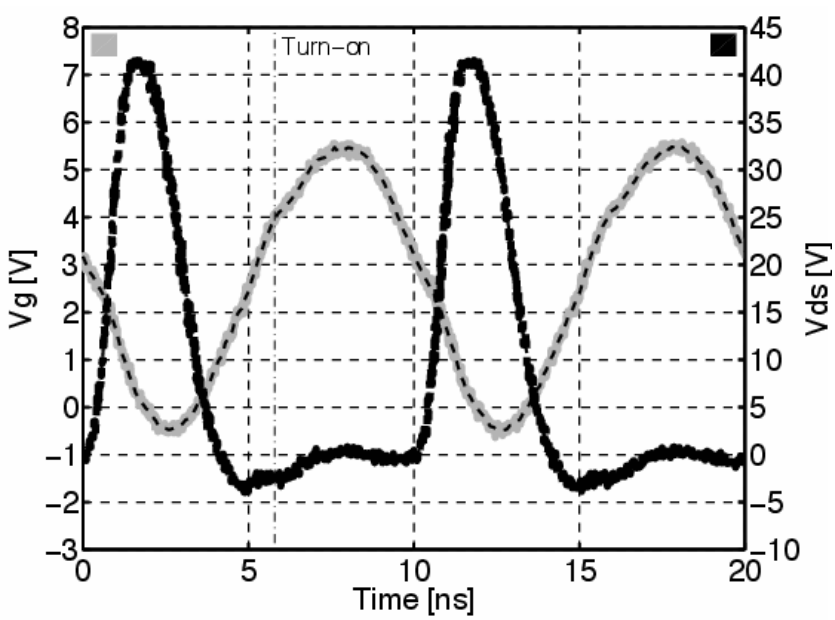

(a) optimal operation

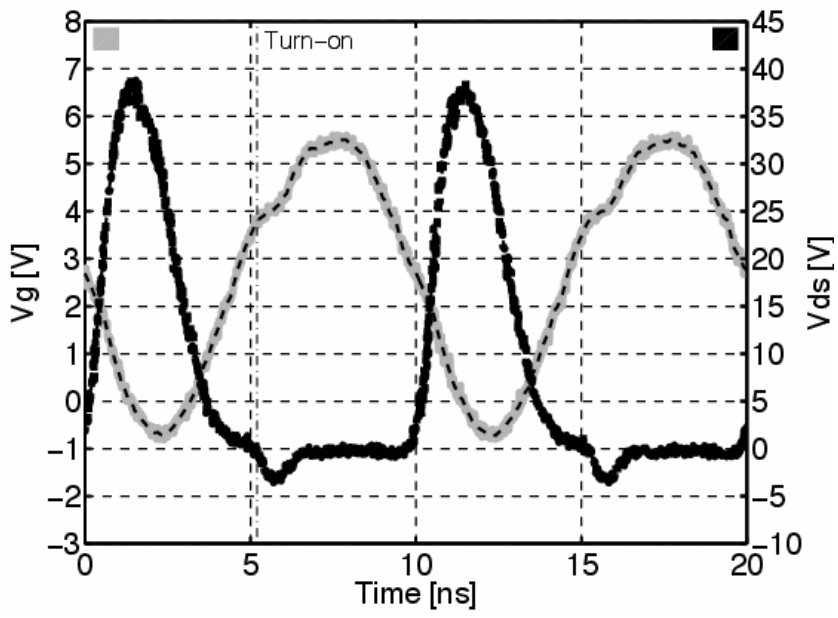

(b) suboptimal operation

Fig. 4: Measurements of gate-source and drain-source voltages $V_{g s}$ and $V_{d s}$ of the power switch and the turn-on instances. Note that the drain-source voltage has an offset of $-0.5 \mathrm{~V}$, due to the oscilloscopes offset.

Simultaneously the output capacitance is highly nonlinear, which was taken into account in the analysis in [20]. There the nonlinearity of the output capacitance $C_{d s}$ is modeled with (1)

$$
C_{d s}\left(V_{c}\right)=\frac{C_{j 0}}{\left(1+\frac{V_{c}}{V_{b i}}\right)^{\gamma}}
$$

where

$C_{j 0} \quad$ is the junction capacitance at $0 \mathrm{~V}$,

$V_{b i} \quad$ is the built-in junction potential, typically $0.5-0.9 \mathrm{~V}$ [29],

$\gamma \quad$ is the junction sensitivity or gradual coefficient. Typically $\gamma=1 / 3$ for gradient junctions, while $\gamma=0.5$ for abrupt junctions [1] hence junction diodes [29], and

$v \quad$ is the junction voltage.

This results in a voltage waveform $V_{c}$ of the power switch as a function of the converters input current $I_{i n}$ and the above

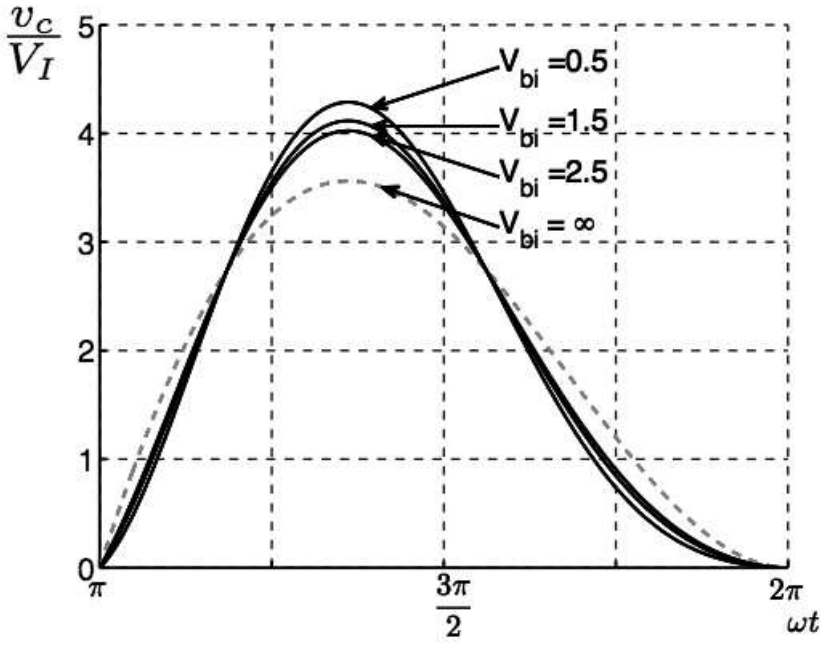

Fig. 5: Voltage waveform of the power switch in relation to DC input voltage for a nonlinear output capacitance from [20]. $V_{b i}$ is the junction potential of the process.

output capacitances parameters as given in (2).

$V_{c}=V_{b i}\left(\left[\frac{I_{i n}(1-\gamma)}{\omega C_{j 0} V_{b i}}\left(\omega t-\frac{3 \pi}{2}-\frac{\pi}{2} \cos \omega t-\sin \omega t\right)+1\right]^{\frac{1}{1-\gamma}}-1\right)$

Fig. 5 shows the relative voltage waveform of the power switch as a function of time and junction potential $V_{b i}$ for a junction sensitivity of $\gamma=0.5$.

The remaining components of the power stage have been investigated in [20] as well. Thereby most focus is on the inductors, as these are the most volume consuming parts, have the biggest weight and typically a big impact on the overall price of the converter. Therefore the inductors have been integrated as toroids into the printed circuit board (PCB). This process is described in [37] and Fig. 6 shows the principle.

A power stage has been designed to operate in suboptimal mode under consideration of the power switches nonlinear output capacitance. The converters efficiency is in the same area as the one presented in II-A and again limited by a high on-resistance, which is due to a low gate drive voltage.

While giving up on the single operating point operation in optimal operation mode, the suboptimal operating converters theoretically allows for different conduction angle operation on the cost of tighter timing to operate in ZVS.

\section{Class-E based SEPIC converter}

For dealing with the efficiency challenge, [38] compared a number of power switches both in simulation and experiment. Furthermore multiple air-core inductors where calculated, designed and implemented. An extraction is shown in Fig. 8. The prototypes reach Q-values beyond 100 and resonance frequencies up to $340 \mathrm{MHz}$. Fig. 9 shows a photograph of the implemented converters. On top of that an effective lineand load regulation scheme was realized in those. The designs where verified in a SEPIC converter (Fig. 7) [39], based on the topologies presented in [40], achieving a power density of 


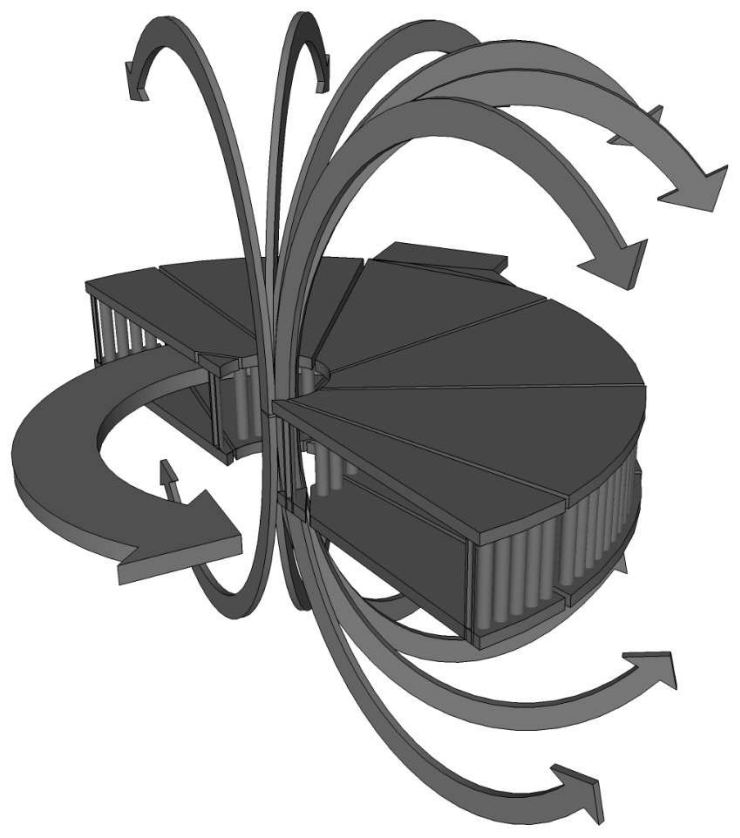

Fig. 6: PCB integrated inductor from [37]. The cross-section of the PCB toroid and the resulting flux arrows are shown.

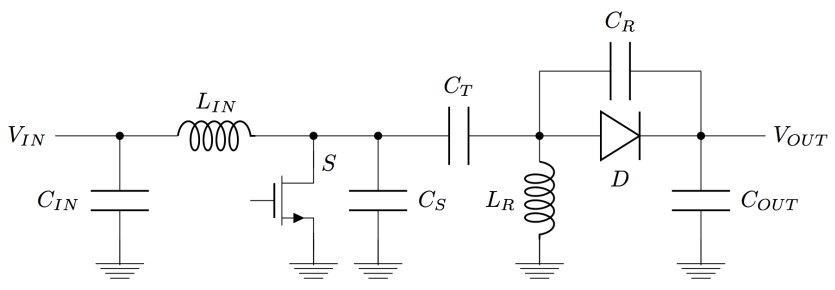

Fig. 7: Schematic of a class-E based SEPIC VHF converter [39].

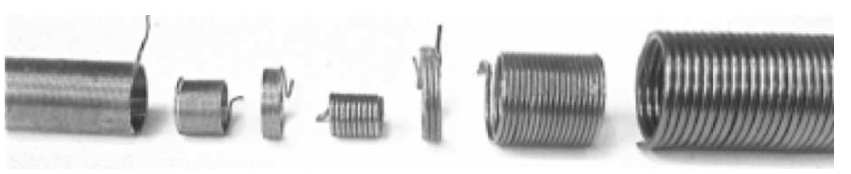

Fig. 8: Photograph of various air core inductors [38].

$8.9 \mathrm{~W} / \mathrm{cm}^{3}\left(146 \mathrm{~W} / \mathrm{in}^{3}\right)$ by switching at $51 \mathrm{MHz}$ for offline LED applications.

Fig. 10 shows the implementation of the final prototype with $70 \mathrm{MHz}$ switching frequency. The voltage step-down ratio of the converters is 10 and the output power range is between 1 and $4 \mathrm{~W}$ at an efficiency within this range beyond $70 \%$.

Compared to the above reported converters, the SEPIC converter is not based on an inverter that delivers a sinusoidal output. The later is crucial in telecommunication applications, when using the class-E inverter as a transmitter, but completely unnecessary demand as an intermediate VHF link within a DC/DC power converter. Relaxing this requirement removes the resonant tank inductor, and therefore the resonant tanks bandpass behavior. On the other hand the rectifier can no

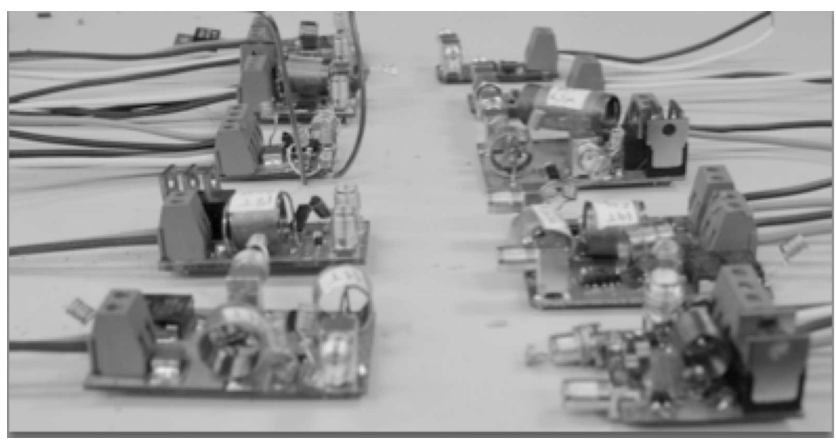

Fig. 9: Photograph of numerous prototypes for comparing measured efficiency with simulations [38].

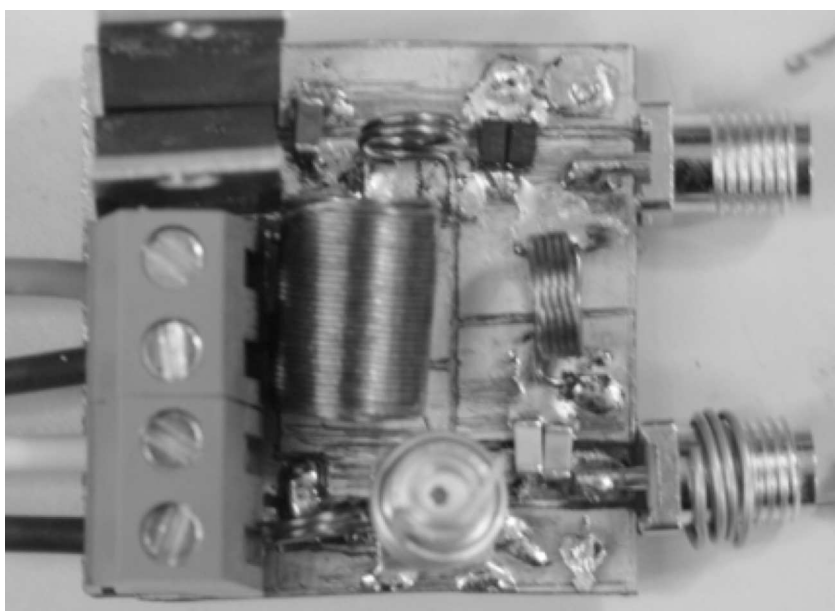

Fig. 10: Photograph of a closed loop low-power VHF converter with an efficiency beyond $70 \%$ from [38]. The TO220 components in the upper left corner are the dummy load resistance.

longer freely be chosen between several topologies, but has to be implemented with a diode, not referenced to ground, which is a disadvantage in some implementation technologies, such as integrated circuits.

\section{Interleaved VHF converters}

Additionally the self-oscillating principle from [19], [24] was combined with the interleave principle from [41], [42] in [43], resulting into a significant efficiency improvement. Interleaving two converter legs allows furthermore to use the ripple cancelation as described in [44] and applied in [41]. The complete schematic of the open loop implementation is shown in Fig. 11. The realized converter is switching at $120 \mathrm{MHz}$, i.e. beyond the FM band, converts an input voltage between 6 and $9 \mathrm{~V}$ into an output current between 0.4 and $0.5 \mathrm{~A}$ and has an efficiency between 80 and $89 \%$ within this operation range. The output power range is 3 to $9 \mathrm{~W}$, corresponding to an output voltage range between $7 \mathrm{~V}$ and $20 \mathrm{~V}$. The converter is designed to drive LEDs. Fig. 12 shows both a SPICE based simulation and a the measurement of the power switches voltage waveforms. Fig. 13 shows the efficiency graph of this converter. 


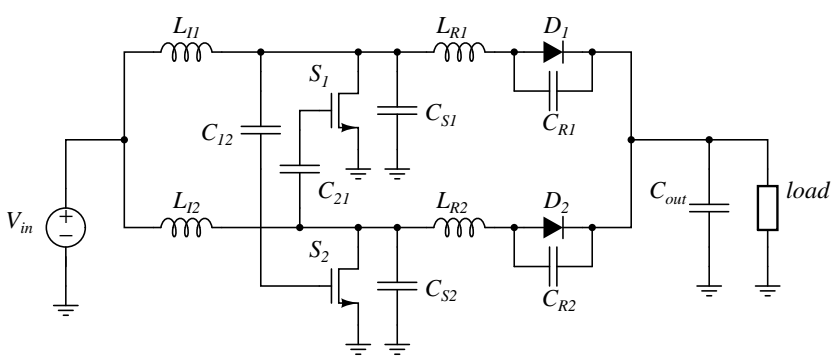

Fig. 11: Full schematic of the open-loop interleaved class-E converter from [43].

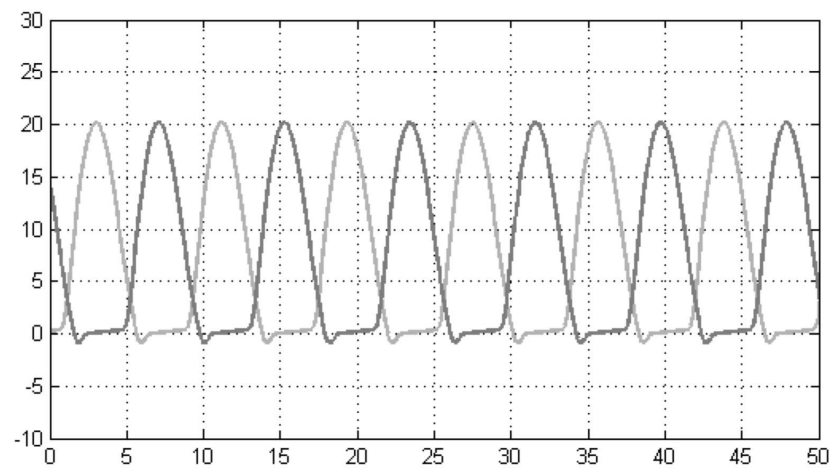

(a) simulated waveforms

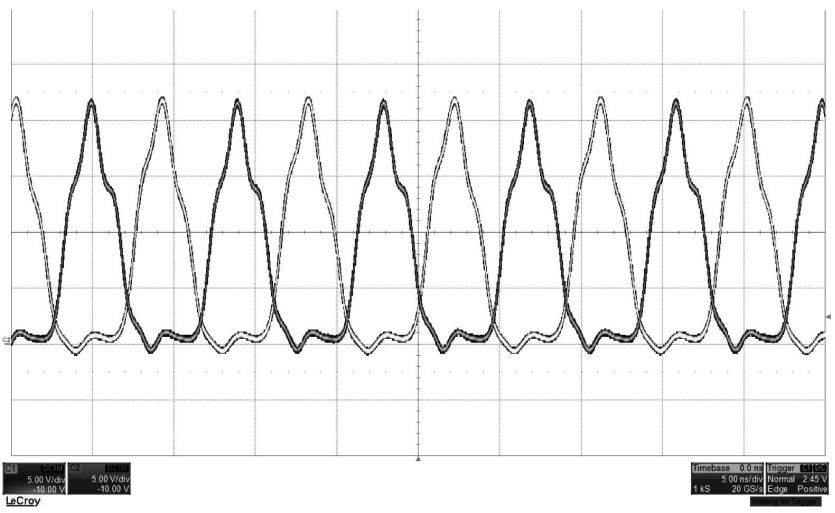

(b) measured waveforms

Fig. 12: Drain-source waveforms of the two power switches in the interleaved converter from [43].

Interleaved converters allow for input and/or output ripple cancellation, segmented power stages, which enables higher power levels [45]. But those converters suffer from different optimal frequencies due to tolerances for each leg, which either might result in beat tones, when operating each of them at its own optimal resonant frequencies, or a non-optimal operation point with respect to efficiency for all legs, when operating all legs at the same frequency.

\section{E. Bidirectional VHF converter}

Replacing the diode in Fig. 1 with a transistor, the class$\mathrm{E}$ amplifier and the class-E synchronous rectifier form a symmetric schematic as shown in Fig. 14. This was realized in [46] and resulted in a bidirectional converter with the same

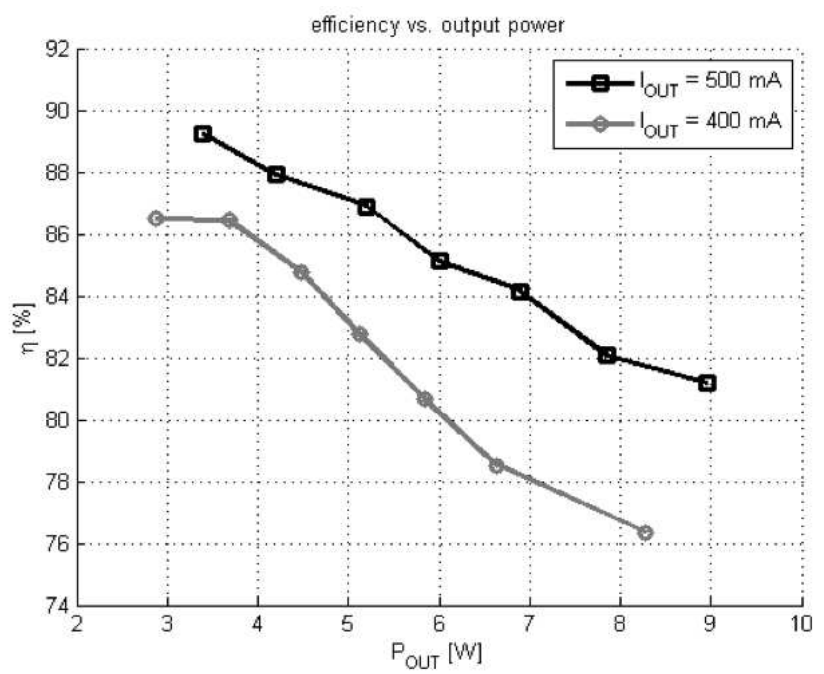

Fig. 13: Efficiency of a battery driven LED driver switching at $120 \mathrm{MHz}$ [43].

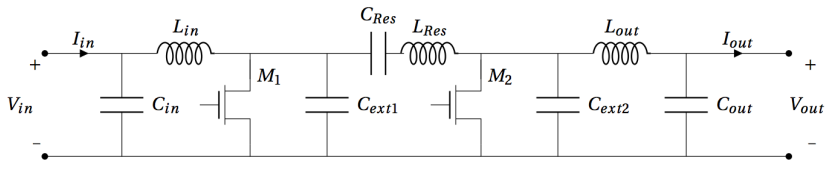

Fig. 14: Schematic of a VHF converter with class-E inverter and synchronous class-E rectifer [46].

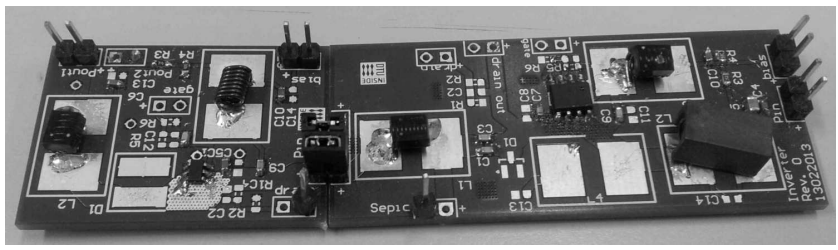

Fig. 15: Photograph of a bidirectional VHF converter [46].

conversion ration from both sides. Operating in the forward mode, the transistor $M_{1}$ is the power switch, operating in class-E mode, and $M_{2}$ is used as synchronous rectifier in class-E operation. In the reverse operating mode, the voltage designated $V_{\text {out }}$ is acting as the input voltage and $M_{2}$ becomes the inverter switch, while $M_{1}$ turns into the synchronous rectifier. The maximum achieved efficiency with this topology was $70 \%$ switching at $30 \mathrm{MHz}$. A photograph of the prototype and thermal pictures of the converter are shown in Fig. 15 and Fig. 16 respectively.

The bidirectional converter allows for lower conduction losses in the rectifier and allows for two-quadrant operation at the cost of an extra gate, which needs a control signal.

\section{Challenges of VHF Converters}

Lately remaining research challenges have been described in [47], [48] This section is summarizing the remaining challenges common in all above described converters with repect to implementation in products. It is dividing the major 


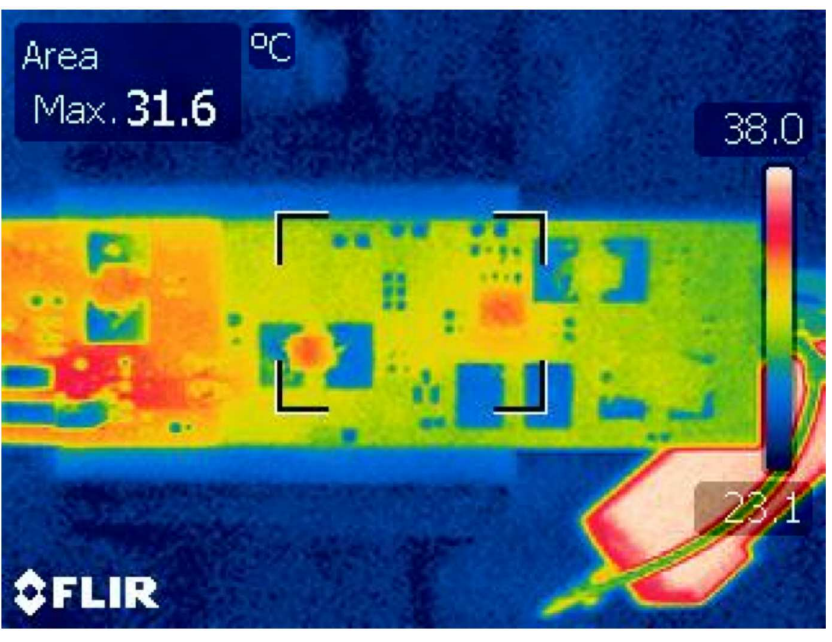

(a) class-E inverter

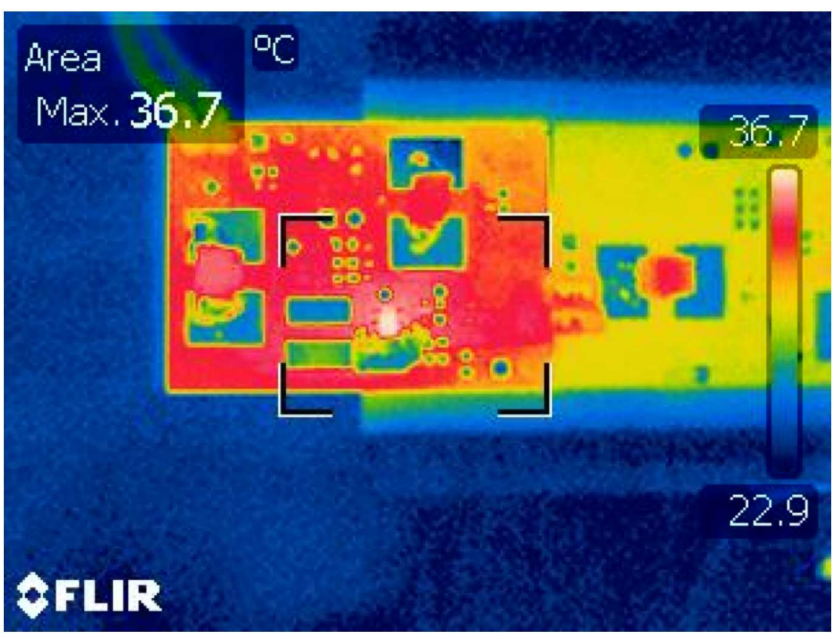

(b) class-E synchronous rectifier

Fig. 16: Thermal photographs of bidirectional VHF converter in thermal equilibrium [46].

remaining show stoppers into three categories and describes those afterwards with respect to existing products on the power supply market, with switching frequencies below the VHF range.

VHF operation of power supplies differs from sub-megahertz operated power supplies (here called traditional power converters) mainly by the following subjects:

- Electronic components, both active and passive,

- Circuit architectures for power stages and control parts,

- Adjacent behavior, such as electromagnetic compatibility (EMC), mechanics and other reliability tests.

\section{A. Components}

Especially inductive components are size, weight and cost optimization limitations in nowadays power circuits. Simultaneously VHF converters provide a major opportunity to overcome those.

Among the challenges are core losses, skin and proximity effect [27], [49]-[54]. For driving further miniaturization of VHF power supplies an obvious next step is to integrate the whole converter in a package (Power Supply in Package $(\mathrm{PSiP})$ ) or even on a single chip (Power Supply on Chip (PwrSoC)). The most challenging part for this goal is the integration of the inductors. Great progress has been made and summarized lately in [55], [56]. However realizations of integrated inductors with Q-values beyond 100 in the relevant frequency ranges remain to be seen. Hybrid concepts as shown in [57] might be applicable. Another challenge within passive components for VHF is the creation of a galvanic isolation barrier [58]-[60].

Despite passive components also active components, i.e. the power semiconductors, need to fulfill other requirements than in usual power supplies [61]-[63]. The parasitic components have a big influence on the design of the overall converter, as they are part of the design parameters. Unlike traditional power stages, the parasitic elements are therefore not considered undesired, but form an integral part of the stage. An example is the output capacitance $C_{o s s}$ of the power semiconductor in a class-E based power supply. According to [19] it is dependent on output power $P_{\text {out }}$, input voltage $V_{\text {in }}$ and switching frequency $f_{s w}$ as shown in (3).

$$
P_{\text {out }}=2 \pi^{2} f_{\text {sw }} C_{\text {oss }} V_{\text {in }}^{2}
$$

This means that the output capacitance $C_{o s s}$ is limiting the maximum switching frequency for a given application, which specifies $P_{\text {out }}$ and $V_{\text {in }}$

\section{B. Architectures}

Where traditional power electronics circuits use square wave gate drive signals, the presented VHF converters so far utilized sinusoidal gate drive [18], [24], [64], [65]. This is mainly due to the input capacitance $C_{i s s}$ of VHF power semiconductors, which require a high peak current at extremely high speed. To consider the drive voltage trapezoidal its rise and fall times have to be less than 1 ns [65]. A trapezoidal or square wave drive would minimize the time of the power switch in linear operation and therefore decreases the losses.

The degrees of freedom in terms of modulation principles are less for VHF converters. Whereas power electronics circuits usually use pulse width modulation or phase modulation, the VHF converters efficiency is dependent on those parameters. Therefore they need to be adjusted statically to avoid losses by leaving the ZVS (or ZCS) range. A way to get around this is to apply burst mode control [17], [64], [66]. This method however introduces another low frequency component in the spectrum, which has to be buffered or filtered at both the inand output of the converter. A requirement that enforces the use of bulky components and therefore is counterproductive to the intended advantages of VHF converters in the first place. While the VHF converters offer good possibilities for fast transient regulations, their low frequency control performance is limited by intrinsic bandpass behaviors through serial capacitors. Even though some rectifiers are available with parallel capacitances and impedance transformation [19], [67], more suitable architectures are missing. Thereby it needs to be taken into account, that the original VHF power circuits are designed to match a defined load (typically the impedance of 
the antenna) and therefore impedance transformation circuits can be realized in a passive way. Power converters however are connected to highly varying loads, i.e. load circuit in idle - drawing no energy from the supply - and full load demanding the maximum output from the supply. Therefore active and lossless impedance matching circuits are required. Having such circuits at hand opens for utilization of the high gain bandwidth in VHF converters for line and load regulation.

\section{Adjacencies}

Lastly the interaction of VHF converters with its physical environment is different than the one of traditional power converters.

On one hand, the electromagnetic interaction between circuits increases, the higher the relevant frequencies are [68]-[71]. Fields are distributed easier both inside the converter and to its surroundings. The electrical behavior also becomes highly dependent on electromechanical interfaces, such as cooling and housing. However the harmonics of the resonant waveforms are falling faster, than the harmonics in hard switched traditional power converters [20]. Also the harmonics of the fundamental switching frequency are spaced wider. That means the distance can be used to place strategically important EMC bands, dependent on the application.

On the other hand, the carefully adjusted operating points of VHF converters (for efficiency purposes) are highly dependent on temperature [19], [20]. Adaptive mechanisms for ensuring optimal operation over industry standard temperature ranges are yet to come.

\section{CONCLUSION}

The merge of techniques used in radio communication electronics and power electronics was pointed out. The development through the previous decades has been revisited and recent developments were summarized. Remaining challenges and the latest advances were described. The implementations of numerous VHF converters were presented. Among them are low-power, high-step-down converters with a switching frequency of $70 \mathrm{MHz}$ and an efficiency beyond $70 \%$ as well as a $120 \mathrm{MHz}, 9 \mathrm{~W}$ LED driver with an efficiency up to $89 \%$. Both converters maintain high efficiencies over a wide load range.

The remaining challenges, that require solutions before VHF converters can be implemented in numerous industrial applications were found to be within the categorizes components, circuit architectures and reliability testing.

\section{REFERENCES}

[1] A. Grebennikov and N.O. Sokal. Switchmode RF power amplifiers. Communications engineering series. Elsevier/Newnes, 2007, ISBN: 9780750679626.

[2] M. K. Kazimierczuk. RF Power Amplifiers. Wiley, 2008, ISBN: 9780470779460

[3] N. O. Sokal, A. D. Sokal. Class E-A new class of high-efficiency tuned single-ended switching power amplifiers. IEEE Journal of Solid-State Circuits, SC-10(3):168-176, June 1975.

[4] N. O. Sokal. Class-E High-Efficiency RF/Microwave Power Amplifiers: Principles of Operation, Design Procedures, and Experimental Verification. Analog Circuit Design, Springer, 2003.
[5] Raab, F.H. Maximum efficiency and output of class-F power amplifiers. IEEE Transactions on Microwave Theory and Techniques, 49(6):11621166, June 2001.

[6] Raab, F.H. Class-F power amplifiers with maximally flat waveforms. IEEE Transactions on Microwave Theory and Techniques, 45(11):20072012, November 1997.

[7] H.L. Krauss, C.W. Bostian, and F.H. Raab. Solid state radio engineering. Wiley, 1980, ISBN: 9780471030188

[8] Baxandall, P.J. Transistor sine-wave LC oscillators. Some general considerations and new developments. Proceedings of the IEE - Part B: Electronic and Communication Engineering, Vol. 106(16):748-758, May 1959.

[9] David A. Jackson. Design and Characterization of a Radio-Frequency $\mathrm{dc} / \mathrm{dc}$ PowerConverter. Master's thesis, Massachusetts Institute of Technology, 2005.

[10] James Raymond Warren III. Cell Modulated dc/dc Converter. Master's thesis, Massachusetts Institute of Technology, 2005.

[11] Robert C. N. Pilawa-Podgurski. Design and Evaluation of a Very High Frequency dc/dc Converter. Master's thesis, Massachusetts Institute of Technology, 2007.

[12] Anthony Sagneri. Design of a Very High Frequency dc-dc Boost Converter. Master's thesis, Massachusetts Institute of Technology, 2007.

[13] Olivia Leitermann. Radio Frequency dc-dc Converters: Device Characterization, Topology Evaluation, and Design. Master's thesis, Massachusetts Institute of Technology, 2008.

[14] Joshua W. Phinney. Multi-resonant Passive Components for Power Conversion. PhD thesis, Massachusetts Institue of Technology, May 2005.

[15] Juan Rivas. Radio Frequency $d c-d c$ Power Conversion. PhD thesis, Massachusetts Institue of Technology, September 2006.

[16] Yehui Han. Circuits and Passive Components for Radio-Frequency Power Conversion. PhD thesis, Massachusetts Institue of Technology, February 2010.

[17] Perreault, D.J.; Jingying Hu; Rivas, J.M.; Yehui Han; Leitermann, O.; Pilawa-Podgurski, R.C.N.; Sagneri, A.; Sullivan, C.R. Opportunities and Challenges in Very High Frequency Power Conversion. Annual IEEE Applied Power Electronics Conference and Exposition, (24):1-14, 2009.

[18] Rivas, J.M. Wahby, R.S. Shafran, J.S. Perreault, D.J. New Architectures for Radio-Frequency DC-DC Power Conversion. IEEE Transactions on Power Electronics, Vol. 21(2):380-393, March 2006.

[19] Andersen Toke. Master Thesis: Radio Frequency Switch-Mode Power Supply. Master's thesis, Technical University of Denmark, 2010.

[20] Peter Kamby. Master Thesis: High Efficiency Radio Frequency Switchmode Power Supply for LED Applications. Master's thesis, Technical University of Denmark, 2011.

[21] Ebert, Jan; Kazimierczuk, Marian. Class E high-efficiency tuned power oscillator. Solid-State Circuits, IEEE Journal of, Vol. 16(2):62-66, April 1981.

[22] Kazimierczuk, Marian K; Krizhanovski, Vladimir G; Rassokhina, Julia V; Chernov, Dmitrii V. Class-E MOSFET tuned power oscillator design procedure. Circuits and Systems I: Regular Papers, IEEE Transactions on, Vol. 52(6):1138-1147, June 2005.

[23] Krizhanovski, Vladimir G; Chernov, Dmitrii V; Kazimierczuk, Marian K. Low-voltage electronic ballast based on class E oscillator. Power Electronics, IEEE Transactions on, Vol. 22(3):863-870, May 2007.

[24] Andersen, T.M. ; Christensen, S.K. ; Knott, A. ; Andersen, M.A.E. A VHF class E DC-DC converter with self-oscillating gate driver. Applied Power Electronics Conference and Exposition (APEC), pages 885-891, March 2011.

[25] Smit, MC and Ferreira, JA and Van Wyk, JD. Application of transmission line principles to high frequency power converters. Power Electronics Specialists Conference PESC'92 Record, (23rd):1423-1430, 1992.

[26] Sander, Sverker. Buck and Boost Converters With Transmission Lines. Power Electronics, IEEE Transactions on, 27(9):4013-4020, September 2012.

[27] Phinney, J.W.; Perreault, D.J.; Lang, J.H. Radio-Frequency Inverters With Transmission-Line Input Networks. IEEE Transactions on Power Electronics, 22(4):1154-1161, July 2007.

[28] Jozwik, Jacek J.; Kazimierczuk, Marian K. Analysis and design of class-E2 DC/DC converter. IEEE Transactions on Industrial Electronics, 37(2):173-183, 1990.

[29] T. Suetsugu, M.K. Kazimierczuk. Analysis and design of class E amplifier with shunt capacitance composed of nonlinear and linear capacitances. IEEE Transactions on Circuits and Systems I: Regular Papers, Vol. 51(7):1261-1268, July 2004. 
[30] Kazimierczuk, Marian K.; Jozwik, Jacek. Class E² narrow-band resonant DC/DC converters. Instrumentation and Measurement, IEEE Transactions on, Vol. 38(6):1064-1068, December 1989.

[31] Kazimierczuk, Marian K and Jozwik, Jacek. Resonant dc/dc converter with class-E inverter and class-E rectifier. Industrial Electronics, IEEE Transactions on, 36(4):468-478, November 1989.

[32] García, José A and Marante, Reinel and de las Nieves Ruiz Lavin, María. GaN HEMT class E2 resonant topologies for UHF DC/DC power conversion. IEEE Transactions on Microwave Theory and Techniques, Vol. 60(12):4220-4229, December 2012.

[33] Gutmann, Ronald J. Application of RF circuit design principles to distributed power converters. Industrial Electronics and Control Instrumentation, IEEE Transactions on, IECI-27(3):156-164, August 1980.

[34] Redl, Richard; Molnar, Bela; Sokal, Nathan O. Class E Resonant Regulated DC/DC Power Converters: Analysis of Operations, and Experimental Results at $1.5 \mathrm{MHz}$. IEEE Transactions on Power Electronics, PE-1(2):111-120, 1986.

[35] Chudobiak, Michael J. The use of parasitic nonlinear capacitors in class E amplifiers. Circuits and Systems I: Fundamental Theory and Applications, IEEE Transactions on, Vol. 41(12):941-944, December 1994.

[36] Suetsugu, Tadashi; Kazimierczuk, Marian K. Comparison of Class-E Amplifier With Nonlinear and Linear Shunt Capacitance. Circuits and Systems I: Fundamental Theory and Applications, IEEE Transactions on, Vol. 50(8):1089-1097, August 2003.

[37] P. Kamby; A. Knott, M. A.E. Andersen. Printed Circuit Board Integrated Toroidal Radio Frequency Inductors. 37th Annual Conference on IEEE Industrial Electronics Society - IECON 2011, October, 2012.

[38] Mickey Madsen. Master Thesis: Offline Very High Frequency Power Converters. Master's thesis, Technical University of Denmark, 2012.

[39] M. P. Madsen, A. Knott, M.A.E. Andersen. Very high frequency resonant DC/DC converters for LED lighting. IEEE Proc. of Applied Power Electronics Conference and Exposition, (28th):835-839, March 2013.

[40] Hu, Jingying; Sagneri, Anthony D; Rivas, Juan M; Han, Yehui; Davis, Seth M; Perreault, David J. High-Frequency Resonant SEPIC Converter with Wide Input and Output Voltage Ranges. Power Electronics, IEEE Transactions on, Vol. 27(1):189-200, January 2012.

[41] Mikolajewski, Miroslaw; Kazimierczuk, Marian K. Zero-voltage-ripple rectifiers and DC/DC resonant converters. Power Electronics, IEEE Transactions on, Vol. 8(1):12-17, January 1993.

[42] Schrom, Gerhard and Hazucha, Peter and Hahn, Jaehong and Gardner, Donald S and Bloechel, Bradley A and Dermer, Greg and Narendra, Siva G and Karnik, Tanay and De, Vivek. A 480-MHz, multi-phase interleaved buck DC-DC converter with hysteretic control. Power Electronics Specialists Conference, 2004. PESC 04. 2004 IEEE 35th Annual, (6):4702-4707, 2004

[43] Kovacevic, Milovan; Knott, Arnold; Andersen, Michael A. E. Interleaved Self-Oscillating Class E Derived Resonant DC/DC Converters. International Conference on Electrical and Computer Systems, August 2012.

[44] Cuk, S.; Erickson R.W. A conceptually new high-frequency switch-mode power amplifier technique eliminates current ripple. Proc. of Powercon 5 , the Fifth National Solid-State Power Conversion Conference, May 1978.

[45] Glaser, John S and Nasadoski, Jeffrey and Heinrich, Richard. A 900W, 300V to 50V Dc-dc Power Converter with a 30MHz Switching Frequency. Applied Power Electronics Conference and Exposition, 2009. APEC 2009. 24th Annual IEEE, pages 1121-1128, 2009.

[46] Jeppe Arnsdorf Pedersen. Master Thesis: Bidirectional Very High Frequency Converter. Master's thesis, Technical University of Denmark, 2013.

[47] Foley, Raymond and Waldron, Finbarr and Slowey, John and Alderman, Arnold and Narveson, Brian and O'Mathuna, Sean Cian. Technology roadmapping for power supply in package (PSiP) and power supply on chip (PwrSoC). Applied Power Electronics Conference and Exposition (APEC), 2010 Twenty-Fifth Annual IEEE, pages 525-532, 2010.

[48] Kassakian, John G and Jahns, Thomas M. Evolving and Emerging Applications of Power Electronics in Systems. Emerging and Selected Topics in Power Electronics, IEEE Journal of, 1(2):47-58, June 2013.

[49] Shanshan Lu; Yuqin Sun; Goldbeck, M.; Zimmanck, D.R.; Sullivan, C.R. 30-MHz Power Inductor Using Nano-Granular Magnetic Material. IEEE Power Electronics Specialists Conference, pages 1773-1776, June 2007.

[50] Sullivan, C.R.; Weidong Li; Prabhakaran, S.; Shanshan Lu. Design and fabrication of low-loss toroidal air-core inductors. IEEE Annual Power Electronics Specialists Conference, (38th):1754-1759, June 2007.
[51] Jizheng Qiu, Sullivan, C.R. Inductor design for VHF tapped-inductor dc-dc power converters. Applied Power Electronics Conference and Exposition, (26th): 142 - 149, March 2011.

[52] Yehui Han; Cheung, G.; An Li; Sullivan, C.R.; Perreault, D.J. Evaluation of magnetic materials for very high frequency power applications. IEEE Power Electronics Specialists Conference, pages 4270-4276, 2008.

[53] Zirath, H.; Rutledge, D.; . An LDMOS VHF class E power amplifier using a high $\mathrm{Q}$ novel variable inductor. IEEE MTT-S International Microwave Symposium, Vol. 1:367-370, June 1999.

[54] M.K. Kazimierczuk. High-Frequency Magnetic Components. John Wiley \& Sons, 2009, ISBN: 9780470714539.

[55] Cian Ó Mathúna, Ningning Wang, Santosh Kulkarni, Saibal Roy. Review of Integrated Magnetics for Power Supply on Chip (PwrSoC). IEEE Transactions on Power Electronics, Vol. 27(11):4799-4816, November 2012.

[56] Jizheng Qiu, Sullivan, C.R. Design and Fabrication of VHF Tapped Power Inductors Using Nanogranular Magnetic Films. IEEE Transactions on Power Electronics, Vol. 27(12):4965-4975, December 2012.

[57] H. Schneider, T. Andersen, A. Knott, M.A.E. Andersen. Hybrid winding concepts for toroids. Energy Conversion Congress and Exibition, June 2013.

[58] Bowman, W.C.; Balicki, F.T.; Dickens, F.T.; Honeycutt, R.M.; Nitz, W.A.; Strauss, W.; Suiter, W.B.; Ziesse, N.G. A resonant DC-toDC converter operating at 22 Megahertz. Applied Power Electronics Conference and Exposition, (3):3-11, 1988.

[59] Sagneri, A.D. ; Anderson, D.I. ; Perreault, D.J. Transformer synthesis for VHF converters. International Power Electronics Conference (IPEC), pages 2347-2353, June 2010

[60] J. Pejtersen, J.D. Mønster, A. Knott. Development and verification of printed circuit board toroidal transformer model. IEEE Proc. of Applied Power Electronics Conference and Exposition, (28th):1654-1659, March 2013.

[61] Warren, J.R. ; Rosowski, K.A. ; Perreault, D.J. Transistor Selection and Design of a VHF DC-DC Power Converter. IEEE Transactions on Power Electronics, Vol. 23(1):27-37, January 2008.

[62] Spiazzi, G. ; Mattavelli, P. ; Rossetto, L. Effects of Parasitic Components in High-Frequency Resonant Drivers for Synchronous Rectification MOSFETs. IEEE Transactions on Power Electronics, Vol. 23(4):20822092, July 2008.

[63] Kuang Sheng ; Yongxi Zhang ; Liangchun Yu ; Ming Su ; Zhao, J.H. . High-Frequency Switching of SiC High-Voltage LJFET. IEEE Transactions on Power Electronics, Vol. 24(1):271-277, January 2009.

[64] Pilawa-Podgurski, R.; Sagneri, A.D.; Rivas, J.M.; Anderson, D.I.; Perreault, D.J. Very-High-Frequency Resonant Boost Converters. IEEE Transactions on Power Electronics, 24(6):1654-1665, June 2009.

[65] Tatsuta, T. ; Ishitani, Y. ; Suetsugu, T. Gate power loss of class E amplifier with rectangular wave gate drive. TENCON 2010 IEEE Region 10 Conference, pages 1784-1787, November 2010.

[66] Rivas, J.M. ; Jackson, D. ; Leitermann, O. ; Sagneri, A.D. ; Yehui Han ; Perreault, D.J. . Design Considerations for Very High Frequency dc-dc Converters. Power Electronics Specialists Conference, pages 1-11, June 2006.

[67] M.K. Kazimierczuk and D. Czarkowski. Resonant Power Converters. John Wiley \& Sons, 2011, ISBN: 9780470905388.

[68] Liu, D.H.; Jiang, J.G. High frequency characteristic analysis of EMI filter in switch mode power supply (SMPS). Power Electronics Specialists Conference, Vol. 4:2039-2043, June 2002.

[69] Wang, C.P.; Liu, D.H.; Jiang Jianguo. Study of coupling effects among passive components used in power electronic devices. Power Electronics and Motion Control Conference, Vol. 3:1500-1504, August 2004.

[70] Liyu Yang; Bing Lu; Wei Dong; Zhiguo Lu; Ming Xu; Lee, F.C. Odendaal, W.G. Modeling and characterization of a $1 \mathrm{KW}$ CCM PFC converter for conducted EMI prediction. Applied Power Electronics Conference and Exposition, Vol. 2:763-769, February 2004.

[71] Shuo Wang. Characterization and Cancellation of High-Frequency Parasitics for EMI Filters and Noise Separators in Power Electronics Applications. $\mathrm{PhD}$ thesis, Virginia Polytechnic Institute and State University, Blacksburg, Virgina, May 2005. 


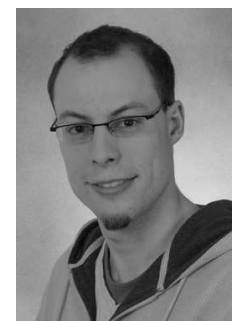

Arnold Knott (M'10) received the DiplomIngenieur $(\mathrm{FH})$ degree from the University of Applied Sciences in Deggendorf, Germany, in 2004. From 2004 until 2009 he has been working with Harman/Becker Automotive Systems GmbH in Germany and USA, designing switch-mode audio power amplifiers and power supplies for automotive applications. In 2010 he earned the Ph.D. degree from the Technical University of Denmark, Kongens Lyngby, Denmark working on a research project under the title "'Improvement of out-of-band Behaviour in Switch-Mode Amplifiers and Power Supplies by their Modulation Topology"'. From 2010 to 2013 he was Assistant Professor and since 2013 Associate Professor at the Technical University of Denmark. His interests include switch-mode audio power amplifiers, power supplies, active and passive components, integrated circuit design, acoustics, radio frequency electronics, electromagnetic compatibility and communication systems.

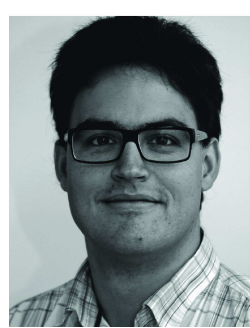

land.
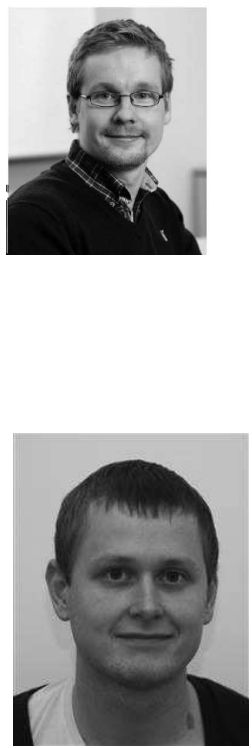

Jeppe A. Pedersen received his B.Sc. and M.Sc. degrees from the Technical University of Denmark (DTU), Kongens Lyngbt, Denmark in 2010 and 2013 respectively. His research interests are very high frequency (VHF) switch-mode power supplies, bidirectional power conversion and LED drivers. Currently Jeppe is research assistant the the Technical University of Denmark. respectively. His research interests are very high frequency (VHF) switch-mode power supplies, high current power conversion and pulsed power.

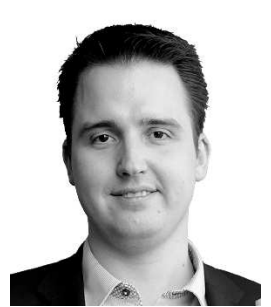

Mickey P. Madsen (S'12) received the B.Sc.E.E. and M.Sc.E.E. degrees from the Technical University of Denmark, Kongens Lyngby, Denmark, in 2009 and 2012, respectively.

$\mathrm{He}$ is currently working towards a Ph.D. degree in power electronics under the title "Very High Frequency Switch Mode Power Supplies". His research interests includes switch-mode power supplies, resonant inverters/converters, wide band gab semiconductors, solid state (LED) lighting and radio frequency electronics.

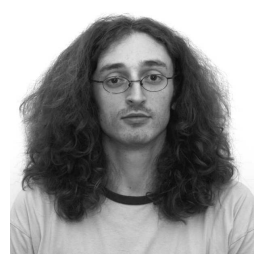

Milovan Kovacevic received the B.Sc. and M.Sc. degrees from the University of Belgrade, Serbia, in 2008 and 2010, respectively. He is currently working toward the Ph.D. degree at the Department of Electrical Engineering, Technical University of Denmark, Kgs. Lyngby, Denmark.

His research interests include high-frequency power electronics, resonant and soft-switching techniques, analog and mixed-signal circuit design, and control of power converters.

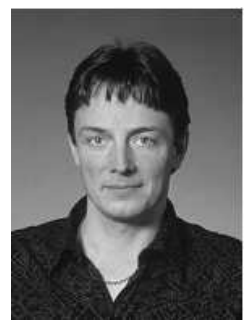

Michael A. E. Andersen (M'88) received the M.Sc.E.E. and Ph.D. degrees in power electronics from the Technical University of Denmark, Kongens Lyngby, Denmark, in 1987 and 1990, respectively. $\mathrm{He}$ is currently a Professor of power electronics at the Technical University of Denmark. Since 2009, he has been Deputy Director at the Department of Electrical Engineering. He is the author or coauthor of more than 200 publications. His research interests include switch-mode power supplies, piezoelectric transformers, power factor correction, and switchmode audio power amplifiers. 